\title{
Herança clássica em duas cançóes castelhanas DE MANUEL BOTELHO DE OLIVEIRA
}

\author{
Anne Navarro Miranda* \\ Uni-BH
}

\begin{abstract}
RESU MO
O presente artigo tem como objeto o estudo de duas canções escritas em espanhol pelo poeta Manuel Botelho de Oliveira, e publicadas na obra Música do Parnasso, de 1705. Nelas, como de resto em vários outros poemas de Botelho de Oliveira, a mitologia clássica comparece como indício da adesão ao código literário de seu tempo. Esse esforço do poeta baiano, por incluir-se no cânone da poesia da época, representou um importante marco para a literatura brasileira.
\end{abstract}

\section{PALAVRAS - CHAVE}

Literatura brasileira, Barroco, Manuel Botelho de Oliveira

ano de 1705 representou, para a literatura brasileira, um importante marco: foi quando se inaugurou em nosso país, com Música do Parnasso, de Manuel Botelho de Oliveira, a tradição da publicação de livros de poesia. De fato, aquela obra poética foi a primeira publicada por autor brasileiro vivo.

Além desse seu caráter inaugural, o livro de Botelho de Oliveira merece atenção por outros motivos mais. Nele, o poeta brasileiro exercitou o seu talento nas quatro línguas consideradas na época idôneas para o exercício da poesia - a portuguesa, a castelhana, a italiana e a latina. Cada uma dessas quatro partes foi denominada "coro". Esses coros se organizaram de modo que, em cada um deles, houvesse exemplares das formas mais adequadas à expressão daquelas línguas. Assim, na parte escrita em português, há sonetos, madrigais, décimas, redondilhas, romances, panegíricos, oitava e uma silva; na parte escrita em espanhol, o poeta compôs sonetos, madrigais, décimas, romances e cancões; na parte escrita em italiano, encontramos sonetos e madrigais; e na escrita em latim, podem-se ler versos descritivos de um leão, epigramas e um idílio em forma de diálogo.

Para estudar a presença da mitologia clássica na obra deste importante poeta do barroco brasileiro - presença essa que, entre outros fatores, representou a adesão do poeta ao código poético da época, garantindo a inclusão da obra no cânone literário do seu tempo -, escolhemos duas das canções escritas no idioma de Cervantes: "Descrição da manhã" e "Descrição do ocaso". ${ }^{1}$ Como indicam seus títulos, elas tratam de temas

\footnotetext{
*anne.nm@bol.com.br

${ }^{1}$ Todos os poemas da obra receberam títulos em língua portuguesa.
} 
que, antitéticos ou opostos, encerram uma unidade: as duas canções escolhidas para análise tratam dos dois momentos extremos do dia.

Preliminarmente, no entanto, faz-se necessário propor uma teoria da forma canção.

\section{A FORMA CANÇÃO}

A palavra "canção" deriva do latim "cantione $(\mathrm{m})$ ", acusativo de "cantio", "onis', que significa "canto", "canção". Como o demonstra a etimologia, a forma poética esteve, em sua origem, relacionada à melodia, e dela foi-se dissociando gradativamente durante a sua evolução, até tornar-se autônoma por volta da segunda metade do século XV.

A canção originou-se na Provença: segundo Massaud Moisés, ${ }^{2}$ foi criada por Giraud de Borneil (1165-1199). Essa modalidade, denominada na terminologia moderna "canção trovadoresca", designada inicialmente por "cansó" ou "chanson", destinava-se ao canto. Ao longo da evolução da lírica trovadoresca, a "cansó” passou do sul da França à Península Ibérica - onde recebeu as denominações de "canción" e "cantiga" -, ao norte da França, à Inglaterra e à Itália. Nesta última região, adaptando-se às conjunturas locais, a "cansó" provençal sofreu algumas modificações que culminaram no progressivo divórcio entre poesia e música. A "canzone" italiana derivou dos experimentos realizados por Dante (1265-1321) e Petrarca (1304-1374), mais efetivamente por esse último, sobre a base provençal. Atribui-se a Petrarca a fixação, entre as muitas variantes praticadas na época, de um modelo que recebeu o nome de "canção petrarquista" ou "petrarquesca".

A canção petrarquista possui uma estrutura bastante complexa: organiza-se invariavelmente em três partes, que Baehr denominou "fronte", "llave" y "sirima", encontrando-se unidas as duas primeiras por um verso de enlace. O modelo estabelecido por Petrarca apresenta um número indeterminado de estâncias - variável entre quatro e doze, podendo chegar a mais de trinta - rigorosamente simétricas e longas, com pelo menos nove versos cada e extensão média de entre treze e quinze. ${ }^{3}$ Distingue-se do modelo provençal pelo uso obrigatório de versos hendecassílabos e heptassílabos em livre combinação e por terminar sempre por um envio, pelo qual o poeta se dirige à própria canção.

A introdução dessa modalidade de canção na Península Ibérica foi feita pelo poeta catalão Juan Boscán, mas o responsável por sua difusão foi Garcilaso de la Vega. Entre os espanhóis do Século de Ouro, a canção foi usada, de modos vários, por Cervantes, Lope de Vega, Gôngora, Quevedo e outros.

O necessário estudo da forma canção, no âmbito da língua portuguesa, para a análise dos dois exemplares de Manuel Botelho de Oliveira, nos coloca diante de algumas dificuldades relativas à terminologia. Em todas as fontes consultadas o valor da palavra e a sua correspondência com uma forma poética específica não são muito exatos. Rudolf Baehr, por exemplo, na categoria de formas fixas de composição, em que inclui a canção, enumera várias formas poéticas e afirma que o estudo do uso que delas fizeram os poetas

\footnotetext{
${ }^{2}$ MOISÉS. A criação literária: poesia, p. 281.

${ }^{3}$ Cf. BAEHR. Manual de versificación española, p. 344.
} 
espanhóis oferece "una primera dificultad, porque la terminología no es siempre clara, y muchas veces su aplicación es parcial y sujeta a presupuestos teóricos". ${ }^{4}$ Sob a denominação de canção estariam reunidas, na terminologia moderna, segundo esse estudioso, a canção medieval, a canção petrarquista, e a canção alirada. Esta última compreende várias formas derivadas da canção petrarquista, designadas por outros nomes na terminologia antiga, entre os quais figura o de "canção clássica".

A canção alirada, cujo nome deriva da lira de Garcilaso de la Vega, distingue-se da canção petrarquista por possuir estrofes curtas, embora a ela se assemelhe pela disposição simétrica das estâncias, igualmente constituídas pela livre combinação de versos hendecassílabos e heptassílabos. A predominância de um desses versos sobre o outro resulta, respectivamente, numa "canção grave", de caráter solene, ou numa “canção ligeira”, de caráter elegíaco.

No verbete "canção", do Dicionário de literatura dirigido por Jacinto do Prado Coelho, Antônio Coimbra Martins faz uma advertência semelhante acerca da nomenclatura: ele afirma que "torna-se difícil definir e caracterizar a canção porque abrange pelo menos três gêneros literários", ${ }^{5}$ que seriam a canção provençal, a canção italiana ou clássica e a canção romântica. Porque são as que interessam em virtude dos propósitos do presente estudo, trataremos de expor a opinião do autor do verbete acerca das duas primeiras somente. A canção provençal alcançou a Península Ibérica ainda na Idade Média, onde foi praticada, entre outros, pelos trovadores galego-portugueses, com o nome de "cantiga".

A canção italiana ou clássica, por sua vez, alcançou a Península proveniente da Itália, já nos moldes petrarquistas e é, por oposição às outras duas, a que foi praticada na época barroca. Na literatura de língua portuguesa, a canção italiana ou clássica estaria constituída geralmente por três partes: introdução, texto e finda, embora pudesse o poeta prescindir da primeira dessas partes. As estâncias do "texto" dessa modalidade de canção têm rimas simétricas e alternam o verso heróico, com o quebrado correspondente, sempre segundo o mesmo esquema. O termo "finda", cujo registro não consta dos dicionários de língua portuguesa mais recentes, sendo certamente derivado do galego-português "fiinda", será substituído por nós pelo termo "envio", que designa a estrofe que, possuindo a metade do número de versos das anteriores, tem como assunto uma apóstrofe que o poeta destina à própria canção. Embora Antônio Coimbra Martins afirme que a "finda" tenha a metade do número de versos da estância, as canções de Manuel Botelho de Oliveira têm, todas elas, um envio de três versos apenas, quando as estâncias apresentam cinco, seis, sete, oito ou nove versos. Camões também, em pelo menos uma ocasião, utilizou envio de três versos em canção de modelo petrarquista, ou seja, com estâncias em que o número de versos era bem maior.

O uso impreciso do termo "canção" pelos estudiosos fica demonstrada pelos exemplos de Baehr e Antônio Coimbra Martins, dos quais se extrai uma constatação: a palavra canção não tem um significado preciso como termo definidor de uma forma

\footnotetext{
${ }^{4}$ BAEHR. Manual de versificación española, p. 313.

${ }^{5}$ MARTINS. Canção, v. I, p. 140.
} 
poética. Por ser este um campo em que a terminologia é insegura, adotaremos o termo "canção alirada", que, sendo mais abrangente que o termo canção italiana ou clássica, consideramos ser o mais adequado à forma praticada por Manuel Botelho de Oliveira.

Por canção alirada entendemos a forma poética constituída por um texto - com estâncias curtas, simétricas entre si - e um envio - por meio do qual o poeta se dirige à canção. Naturalmente, ela se caracteriza pelo uso, em livre combinação, de versos hendecassílabos e heptassílabos.

\section{A MANHÃ E O OCASO}

Manuel Botelho de Oliveira, na obra Música do Parnasso, compôs dez canções. Os elementos comuns a todas elas são os versos hendecassílabos e heptassílabos, em combinação livre, e o uso do envio de três versos. Foi rigoroso o poeta no uso das rimas, obedecendo a um esquema básico proposto na primeira estância - e variável, de canção para canção -, que se repete nas demais estâncias e, parcialmente, no envio.

Considerados esses aspectos, veremos a seguir de que modo Manuel Botelho de Oliveira fez uso da forma canção, a partir de dois exemplares. A primeira delas intitula-se "Descrição da manhã".

\section{DESCRIÇÃo DA MANHÃ \\ CANÇÃO I \\ I}

Aurora vengativa

De nublados enojos,

Con que al día agravió noche estrellada,

Lucidamente airada,

Castigando a la noche fugitiva

Sus obscuros despojos,

El manto le rompió, cegó sus ojos.

\section{II}

De flores coronada

Derrama dulcemente

El néctar matutino al Sol infante,

Que se mece brillante,

Siendo el rocío leche destilada,

Que en niñez de viviente

Leche el Alba le dá, ${ }^{6}$ cuna el Oriente.

${ }^{6}$ Esta forma do verbo "dar" atualmente não é acentuada. Conservamos a grafia verificada na edição de Música do Parnaso realizada por Antenor Nascentes, de 1953, por nós adotada. 
De suerte que luciendo

Con aplauso canoro,

Del Rey del Cielo es Nuncia brilladora,

Y de la roja Aurora,

Como de roja flor, el Sol naciendo,

Brota en bello tesoro

La flor de rosicler, el fruto de oro.

\section{IV}

Sale el farol radiante,

Alma hermosa de Mayos

Pestañeando al día luz dudosa,

$Y$ si es en gracia hermosa

Del Hemisferio claro ojo flamante,

Forma en rojos ensayos

Por frente el Cielo, por pestañas rayos.

$$
\mathrm{V}
$$

Tirando al coche, luego

Calor ardiente ahuman

Los caballos en calles de esplendores,

Y en lucidos ardores

Estrellas pisan, y relinchan fuego,

Y porque más presuman,

Púrpura ruedan, resplandor espuman.

VI

El Cielo venerado

Con plácida armonía,

Que alterna al aire volador desvelo,

Con reverente celo

Al Cielo le festejan lo sagrado

En cultos de alegría,

Siendo lámpara el Sol, templo el día.

\section{VII}

El Oriente vestido

De purpúreos candores

Jazmines viste, rosas purpurea,

Y si de luz se asea,

Luminoso se ve, se ve florido

De suerte, que en primores

Jardín de rayos es, Cielo de flores.

Canción, si quieres ser eternizada,

Di que en calladas tintas

Cuando pintas el Sol, Anarda pintas. 
Essa canção possui sete estâncias, cada uma com sete versos, que assim se distribuem: o primeiro, o segundo, o quarto e o sexto são heptassílabos, e os outros três, hendecassílabos. Há, portanto, discreta predominância do metro mais curto, com o conseqüente tom ligeiro, que se associa às imagens luminosas do amanhecer. No envio, pelo contrário, os hendecassílabos dominam, rebaixando o tom ligeiro do poema, em associação com a imagem de Anarda, musa rigorosa e cruel.

A disposição de estâncias e versos, consoante ao rigor da forma, é a seguinte:

\begin{tabular}{|c|c|c|c|c|c|c|c|}
\hline I & II & 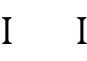 & V & VI & VII & envio & \\
\hline 7a & $7 \mathrm{c}$ & $7 \mathrm{f}$ & $7 \mathrm{e}$ & $7 \mathrm{k}$ & $7 \mathrm{n}$ & $7 \mathrm{q}$ & \\
\hline $7 b$ & $7 \mathrm{~d}$ & $7 \mathrm{~g}$ & $7 \mathrm{i}$ & $7 \mathrm{t}$ & $7 \mathrm{v}$ & $7 \mathrm{~m}$ & \\
\hline $11 \mathrm{c}$ & $11 \mathrm{e}$ & $11 \mathrm{~h}$ & $11 j$ & $11 \mathrm{~m}$ & $11 p$ & $11 \mathrm{r}$ & \\
\hline $7 \mathrm{c}$ & $7 \mathrm{e}$ & $7 \mathrm{~h}$ & $7 \mathrm{j}$ & $7 \mathrm{~m}$ & $7 \mathrm{p}$ & $7 \mathrm{r}$ & \\
\hline $11 \mathrm{a}$ & $11 \mathrm{c}$ & $11 \mathrm{f}$ & $11 \mathrm{e}$ & $11 \mathrm{k}$ & $11 \mathrm{n}$ & $11 \mathrm{q}$ & $11 \mathrm{c}$ \\
\hline $7 \mathrm{~b}$ & $7 \mathrm{~d}$ & $7 \mathrm{~g}$ & $7 \mathrm{i}$ & $7 t$ & $7 \mathrm{v}$ & $7 \mathrm{~m}$ & $7 \mathrm{~s}$ \\
\hline $11 \mathrm{~b}$ & $11 \mathrm{~d}$ & $11 \mathrm{~g}$ & $11 \mathrm{i}$ & $11 \mathrm{t}$ & $11 \mathrm{v}$ & $11 \mathrm{~m}$ & $11 \mathrm{~s}$ \\
\hline
\end{tabular}

As colunas representam as estâncias; as linhas, os versos; os números em cada célula, o número de sílabas do verso; as letras, as rimas.

Conforme se pode notar, os sete versos em todas as estâncias se dispõem do seguinte modo: o primeiro, de sete sílabas, rima com o quinto, de onze; o segundo, de sete sílabas, rima com o sexto, que também é heptassílabo, e com o sétimo, hendecassílabo; e o terceiro, de onze sílabas, rima com o quarto, de sete. O envio retoma o esquema dos três últimos versos das estâncias, o que resulta em um verso solto e rimas emparelhadas nos dois últimos.

No caso da canção "Descrição da manhã", conforme anuncia o título, a canção trata da descrição da manhã. No entanto, a leitura de suas sete estâncias revela que o quadro descrito não corresponde a todo o período matutino, limitando-se ao momento em que surgem os primeiros sinais do dia. A descrição que se faz é a do alvorecer, instante compreendido entre os últimos resquícios da noite e o pleno surgimento do sol, o qual, no entanto, não chega a erguer-se do "oriente". A canção retrata não um período de tempo, mas um instante. Sob esse aspecto, esta canção se vincula à tradição da alba, forma de composição que tem por motivo a aproximação do dia e que remonta à poesia trovadoresca provençal. ${ }^{7}$

Ao tratar de manifestações da arte barroca verificadas na pintura, Heinrich Wölfflin elaborou o conceito de "forma aberta", que corresponde a todo o tipo de representação cujo conteúdo ultrapassa os limites do quadro. Nas obras de arte que encontram expressão em forma aberta, verifica-se uma tendência a "não permitir que o quadro resulte num fragmento do mundo que exista apenas por si e para si, mas num espetáculo passageiro,

${ }^{7}$ CAMPOS. Pequeno dicionário de arte poética, p. 14-15. 
do qual o observador tem a sorte de participar somente por alguns instantes". ${ }^{8}$ O leitor, ou observador, é chamado a usufruir o breve instante que marca o nascimento do novo dia.

A palavra "aurora", que inaugura a primeira estância do poema - e que comparece, também, na estância seguinte - é um indício claro de que o poeta recorre à mitologia clássica para levar a cabo a tarefa de descrever a alvorada. Essa presença do mito na canção é mais uma das marcas da adesão de Manuel Botelho de Oliveira ao código literário de seu tempo. O mito resulta do esforço realizado pelo homem para compreender e dominar os fenômenos da natureza. Ele representa os anseios da sociedade que o criou; pertence a um mundo dramático de ações, em que figuram forças e poderes presentes nos fenômenos da natureza.

Torna-se oportuno, nesse momento da análise, que nos sirvamos de algumas idéias de Ephraim Lessing relativas à natureza do texto literário. Na obra intitulada Laocoonte, ele afirma que, diferentemente da pintura, que para imitar a realidade se vale de signos figurativos distribuídos no espaço, a literatura usa, para alcançar aquele mesmo fim de imitação da realidade, signos sonoros que se sucedem no tempo. Desse modo, a matéria própria da pintura são os objetos, e a da literatura, as ações. Segundo esse raciocínio, a distribuição justaposta dos signos no espaço da tela resulta necessariamente em uma descrição - embora, por efeito de alusões, possa culminar em uma narração. Quanto à literatura, afirma aquele estudioso que o caráter sucessivo dos signos que a constituem confere a ela uma natureza primeira ligada à narração - é certo, no entanto, que, por alusão, pode a poesia ter como resultado uma descrição. ${ }^{9}$ Essa especificidade da literatura - a de ser uma modalidade artística que se desenvolve no tempo -, de que naturalmente participa a canção em estudo, explica a presença forte de elementos narrativos num poema que promete realizar uma descrição. Para esse mesmo efeito narrativo na descrição da manhã colaboram também as referências à mitologia.

Segundo a mitologia clássica, o deus Apolo, filho de Zeus, era o responsável pela condução do "carro do sol", que percorria o céu arrastado por quatro corcéis e cuja passagem significava a presença da luz, ou seja, do dia. Tal acontecimento se fazia preceder, na mitologia clássica, de outro: segundo a crença dos antigos, cabia à deusa Aurora, irmã do Sol e da Lua, abrir todas as manhãs, com os seus dedos cor-de-rosa, as portas do céu para a passagem do carro do sol. Na tradução da Odisseia feita por Manuel Odorico Mendes, bela é a imagem criada, na abertura do Livro II, da luz matutina que ilumina o ato de vestir-se Ulisses: "veste-se, à luz dedirrósea da aurora". ${ }^{10}$ A Aurora, também denominada Alba ou Alva, por sua clara relação com os acontecimentos próprios do amanhecer, tem sido representada sobre um carro puxado por cavalos brancos, espargindo orvalho, vestida de branco e coroada de raios. Por esse motivo, ela é a deusa que precede e anuncia a luz, e por isso tem sido associada ao começo de um novo dia e de uma nova vida.

O texto da canção, a partir da intervenção das alegorias, recria, desde os momentos últimos da noite, imagens relacionadas aos primeiros instantes do dia e ao momento de

${ }^{8}$ WÖLFFLIN. Conceitos fundamentais da história da arte, p. 167-209.

${ }^{9}$ Cf. LESSING. Laocoonte, p. 165-173.

${ }^{10}$ HOMERO. A Odisséia, canto II, v.1, p. 29, em tradução de Odorico Mendes. deve ser citado pelo n⿳o de versos. Assim: Homero. Odisséia, canto ......, vv. ..... em tradução de Odorico Mendes. 
sua afirmação. Para criar tal ambiente, o poeta se vale de palavras que ou sugerem as cores próprias de cada momento, ou são a própria designação dessas cores. Assim, da primeira à última estância, observa-se uma progressiva mudança nas cores com que se vai pintando a paisagem celeste: tais cores vão dos tons escuros próprios da noite que termina - referidos mais claramente na primeira estância - até os tons luminosos que caracterizam o momento de plena afirmação da manhã, quando o sol já de todo ilumina o horizonte. Entre uns e outros aparecem os tons vermelhos, rosáceos e amarelados com que o nascimento do sol vai tingindo, progressivamente, o céu.

Apesar de ser a primeira imagem alegórica dessa canção, a Aurora tem no poema, como lhe corresponde na mitologia clássica, uma participação secundária na composição da descrição da manhã, cuja personagem mais importante é, como pretendemos demonstrar, o sol. Se a palavra "Sol" aparece somente nas estâncias de números dois, três e seis, e no envio, a presença desse astro está assegurada, ainda, em outras partes do poema, pelo uso de metáforas ou imagens a ele relacionadas. Podemos apontar como exemplos de imagens relacionadas ao sol os cavalos do carro de Apolo, que aparecem na quinta estância, e o oriente vestido das cores que a luz solar cria, na última.

Além dessas imagens, aparecem ainda algumas metáforas, cuja posição central no poema - todas localizadas na terceira e quarta estâncias - funciona como indício da importância que tem o sol na composição do poema. A primeira dessas metáforas, "Rey del Cielo", incorpora o representante de máximo poder na hierarquia terrena, que é a figura real. O sol, relacionado no poema ao poder supremo entre os homens, aparece, em analogia com a estrutura de poder na sociedade humana, como o elemento mais importante, aquele que aparece mais por ter luz mais intensa. Facilmente se passa do sentido próprio da palavra "rei" ao sentido figurado que ela assume na metáfora.

Outra metáfora presente nessa terceira estância é a do "fruto de oro", relacionada à beleza e à cor do ouro, ou, em suma, à luminosidade do amarelo. Ora, essa beleza não é outra que a da luz do sol. Quanto ao fruto, ele resulta do processo do amanhecer, de que é o representante final. Desse modo, da figura inicial, "fruto de oro", pode-se recuperar o termo próprio, o "sol". Operações semelhantes podem ser feitas para retomar, das figuras usadas em cada uma das outras metáforas - "flor de rosicler", na terceira estância; "farol radiante", "alma de mayos" e "ojo flamante del Hemisfério", na quarta - o termo próprio que lhes corresponde, o sol. A representação obtida pela localização desse conjunto de metáforas cultas no poema equivale à figura do sol, que é circular e, portanto, pressupõe um centro. O sol, no centro do poema, deriva das metáforas que se usam para designálo, ao modo de seus raios:

FIGURA 1

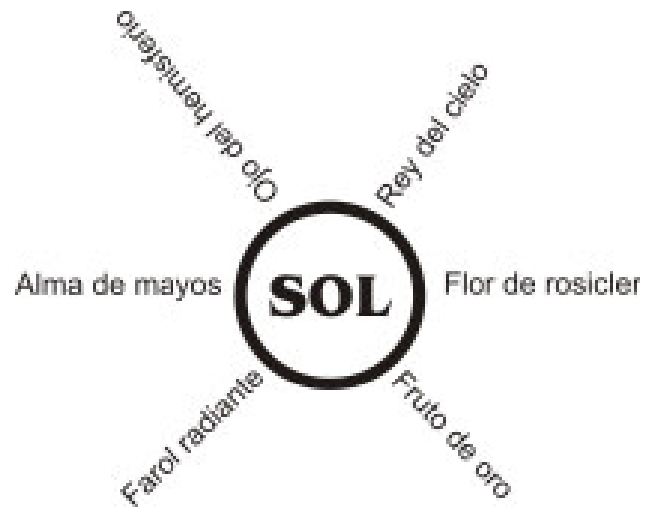


Em virtude talvez da vitalidade própria daquilo que acaba de nascer, daquilo que é vida em potência, no poema tudo é movimento: a noite foge, o sol infante se mexe no berço, os cavalos puxam o carro do sol e energicamente pisam estrelas, relinchando fogo.

Surpreendentemente, no envio, aparece a figura de Anarda, figura convencional de mulher e musa do poeta, a quem ele dedica a maioria dos poemas do livro. A essa altura da composição, o poeta, dirigindo-se à canção, recomenda-lhe que, se quiser eternizar-se, transfira a Anarda as "calladas tintas" com que pintou o sol. Nesse ponto pode-se afirmar que nem o brilho do sol é suficiente para ofuscar o brilho de Anarda nem as palavras da língua para traduzir seu esplendor. A beleza do sol, nesta canção, é posta em evidência com a finalidade única de enaltecer a beleza de Anarda.

Essa canção forma, com a que a sucede, um díptico: cada uma realiza a descrição de um dos momentos temporais opostos e complementares que representam o nascimento e a morte de um dia. O jogo de contrários contido nesse motivo era certamente um topos, como se pode depreender do uso que dele fez também Miguel Ângelo, no famoso conjunto de esculturas em mármore que ornamenta o túmulo de Lourenço de Médicis, em Florença. Nele estão representados, sob a forma de duas estátuas jacentes, em posições opostas e simetricamente espelhadas, a aurora e o crepúsculo. A figura da aurora, situada aos pés da estátua de Lourenço, é a de um corpo feminino na posição própria de quem, tendo alcançado o estado de vigília, começa a erguer-se. A expressão dolorosa do rosto parece significar que é difícil a passagem do sono à realidade do dia. A figura do crepúsculo, representado sob os traços de um homem envelhecido, foi colocada em situação de oposição à da aurora, voltando-lhe as costas, como se vê nas figuras que seguem - na primeira delas, pode-se ter uma visão de todo o quadro; nas demais, aparecem, em detalhes, as figuras do crepúsculo e da aurora.

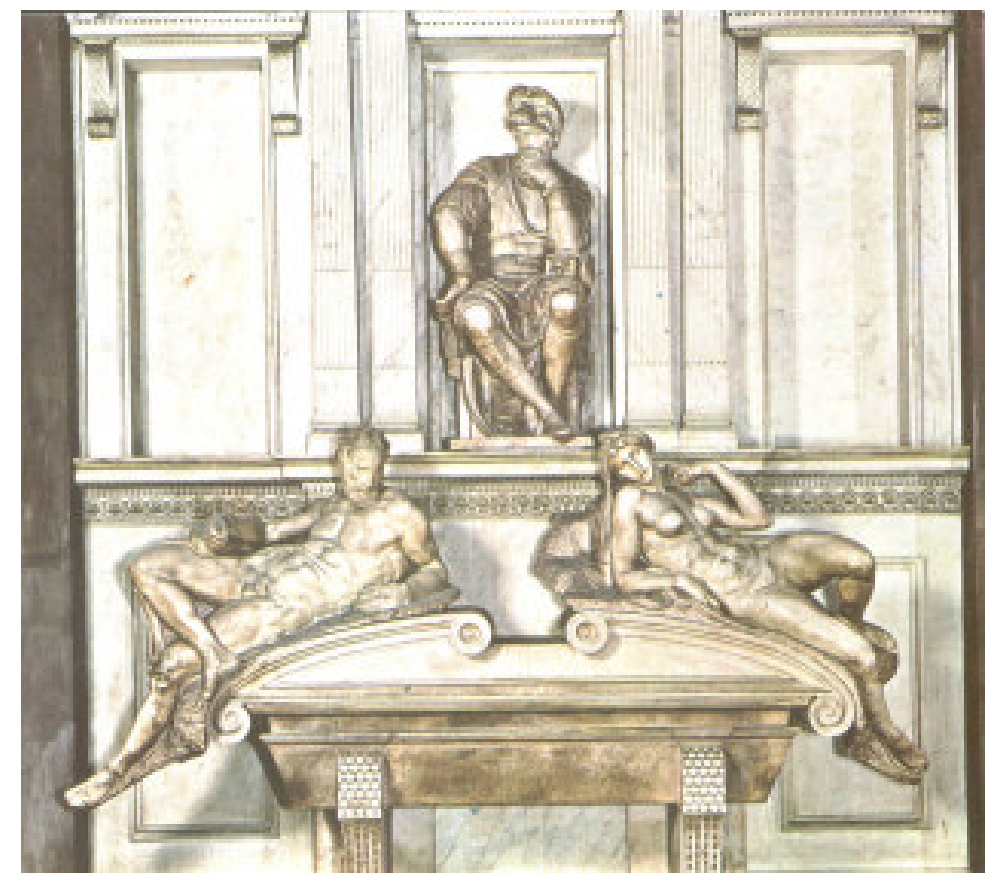

FIGURA 2: Túmulo de Lourenço de Médicis.

Fonte: BERTI. L'Art a Firenze: I capolavori dele gallerie e musei, p. 94-95. 
O díptico de que faz parte a canção "Descrição da manhã" completa-se com a "Descrição do ocaso", que transcrevemos a seguir:

\section{Descrição do OCASO \\ CANÇÃO II \\ I}

Del camino luciente fatigados

Corriendo el cuarto giro todo el día

Buscan a Tetis fría.

Los cuatro brutos de Faetón alados;

Frágiles ya con últimos alientos,

Ya con ardor sedientos

Cuando a Neptuno el hospedaje deben,

Corales pacen, y cristales beben.

II

Bella Anfitrite en cristalinos brazos

Recibe alegremente al Sol brillante,

Que en gala de flamante

Le da de incendio amor, y de oro abrazos;

Y cuando al mar de fuego el Sol parece,

Con las llamas, que ofrece,

Anfitrite en el último sosiego

Recoge en un mar de agua un mar de fuego.

III

Brillando cual antorcha el Sol lustroso,

(Contra las nieblas del obscuro coche,

Que conduce la noche)

Siendo el Cielo aposento luminoso,

Siendo pálida cera el oro ardiente,

Al último occidente

(Porque nuestro Zodíaco no alumbre)

Gastóse el oro, y se extinguió la lumbre.

\section{IV}

Apolo bello bellas ansias siente

Cuando forma crepúsculo dorado

En el cristal salado

Ya con achaques d'esplendor doliente,

Y agonizante con la hermosa vida

Frágilmente lucida

Fluctúa, cuando cierra su tesoro

En urna de cristal el cuerpo de oro. 
Muere el Sol, y las sombras del abismo

Empiezan a salir en vuelo obscuro,

Si bien esplendor puro

De estrellas substitue al parasismo,

Que en el mar sepultado el noble Apolo,

Sirve de templo el polo,

Y al túmulo mortal, porque lo aliñen,

Sombras enlutan, y blandones ciñen.

VI

A favor de la noche resplandece

Al Héspero luciente Citerea,

Que entre la sombra fea

Cuando se esconde el Sol, ella amanece,

Cuando amanece el Sol, escóndese ella,

Siendo a su gracia bella

El Oriente gentil Ocaso ardiente,

El Ocaso mortal hermoso Oriente.

Canción, también me esconde

Entre tinieblas de congoja tarda

La noche de la ausencia el Sol de Anarda.

A canção "Descrição do ocaso" apresenta seis estâncias com oito versos cada, e um envio. Nas estâncias, dos versos empregados, hendecassílabos e heptassílabos, predominam os primeiros: seis dos oito versos de cada uma possuem onze sílabas. No envio, dois versos são hendecassílabos e um é heptassílabo. Essa predominância dos versos longos sobre os breves confere ao poema um caráter grave, solene.

O quadro que segue representa a organização esquemática da canção:

\begin{tabular}{|c|c|c|c|c|c|c|}
\hline I & II & I & V & VI & envio & \\
\hline $11 \mathrm{a}$ & $11 \mathrm{e}$ & $11 \mathrm{i}$ & $11 \mathrm{k}$ & $11 q$ & $11 \mathrm{~g}$ & \\
\hline $11 b$ & $11 \mathrm{f}$ & $11 \mathrm{j}$ & $11 n$ & $11 \mathrm{r}$ & $11 \mathrm{v}$ & \\
\hline $7 b$ & $7 f$ & $7 \mathrm{j}$ & $7 \mathrm{n}$ & $7 \mathrm{r}$ & $7 \mathrm{v}$ & \\
\hline $11 \mathrm{a}$ & $11 \mathrm{e}$ & $11 \mathrm{i}$ & $11 \mathrm{k}$ & $11 \mathrm{q}$ & $11 \mathrm{~g}$ & \\
\hline $11 \mathrm{c}$ & $11 \mathrm{~g}$ & $11 \mathrm{k}$ & $11 \mathrm{w}$ & $11 \mathrm{~s}$ & $11 \mathrm{x}$ & \\
\hline $7 c$ & $7 \mathrm{~g}$ & $7 \mathrm{k}$ & $7 w$ & $7 \mathrm{~s}$ & $7 x$ & $7 y$ \\
\hline $11 d$ & $11 \mathrm{~h}$ & $11 \mathrm{~m}$ & $11 \mathrm{p}$ & $11 \mathrm{u}$ & $11 \mathrm{k}$ & $11 z$ \\
\hline $11 d$ & $11 \mathrm{~h}$ & $11 \mathrm{~m}$ & $11 p$ & $11 \mathrm{u}$ & $11 \mathrm{k}$ & $11 z$ \\
\hline
\end{tabular}

As colunas representam as estâncias; as linhas, os versos; os números em cada célula, o número de sílabas do verso; as letras, as rimas. 


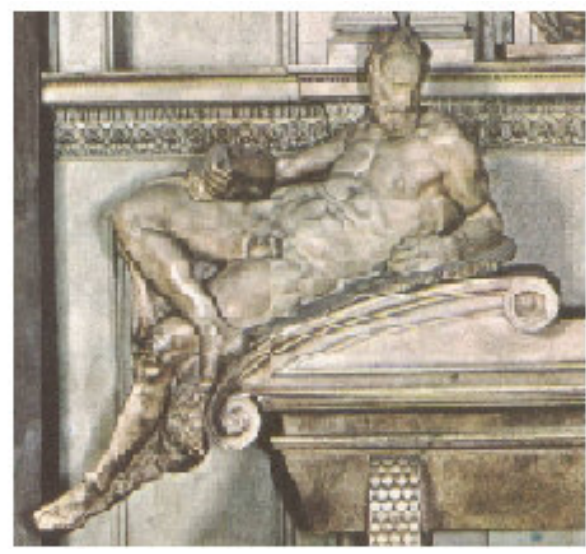

FIGURA 3 - Crepúsculo

Fonte: BERTI. L'Art a Firenze: I capolavori dele gallerie e musei, p. 94-95.

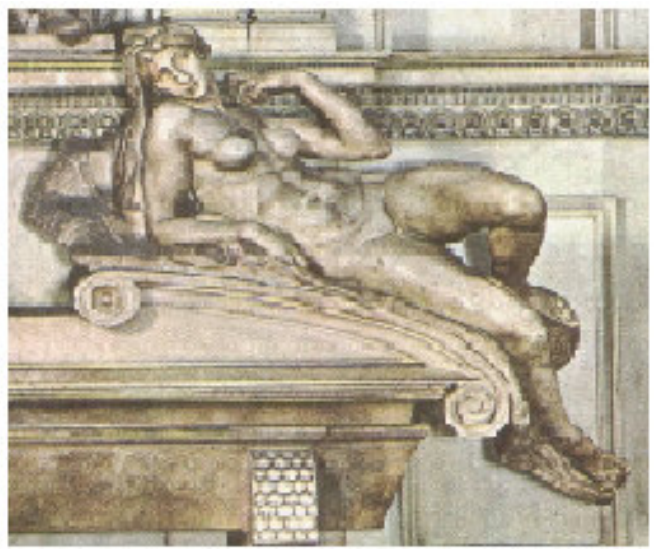

FIGURA 4 - Aurora

Fonte: BERTI. L'Art a Firenze: I capolavori dele gallerie e musei, p. 94-95.

Cada um dos oito versos de cada estância apresenta a seguinte organização: o primeiro verso rima com o quarto, ambos hendecassílabos; $\mathrm{O}$ segundo, hendecassílabo, rima com o terceiro, heptassílabo. O quinto, hendecassílabo, e o sexto, heptassílabo, rimam entre si. Os dois últimos versos, ambos hendecassílabos, também rimam entre si. Portanto, os versos heptassílabos são o terceiro e o sexto. Tal esquema métrico e de rimas é o mesmo em todas as estâncias.

Novamente recorre o poeta ao uso de alegorias relacionadas ao instante que descreve; nesta canção, elas aparecem em número ainda maior que aquele verificado na canção anterior. Assim como na "Descrição da manhã", a canção seguinte tem como motivo um instante do dia. No entanto, se o título da canção anterior apresenta uma certa imprecisão terminológica ao prometer descrever a manhã quando na verdade descreve a alvorada, observa-se, nesta canção, a exatidão com que se empregou no título o vocábulo "ocaso", que significa, na ciência da astronomia, o momento exato em que um astro passa pelo horizonte ocidental.

A adoção do código literário europeu é evidente no poema. Devem-se a essa adesão às convenções de seu tempo as alusões feitas a Netuno, deus do mar, e a Anfitrite, sua esposa, e ainda a referência a Tétis, deusa que habita o oceano e em cuja morada, segundo a crença dos antigos gregos e romanos, o sol se deitava a cada tarde.

A esse conjunto de alegorias marítimas pertencem também os cavalos que puxam o carro do sol, os quais, exaustos do caminho percorrido durante todo o dia, anseiam por chegar ao seu local de descanso, a morada de Tétis no oceano. A menção aos cavalos do carro do sol funciona como elemento de coesão entre as duas canções. Se na primeira delas, a que descreve o amanhecer, os cavalos do carro do sol estão plenos de energia vital - "estrellas pisan, y relinchan fuego", "púrpura ruedan, resplandor espuman" - na segunda, destinada à descrição do ocaso, eles, sedentos, fatigados e frágeis, preparamse para o repouso, usufruindo já - "corales pacen y cristales beben" - da hospitalidade que Netuno lhes oferece.

Os quatro cavalos, sendo os mesmos corcéis indômitos que puxam o carro de Apolo no início da jornada, neste poema não se mencionam como tais, mas como "los cuatro brutos de Faéton alados". Narra a mitologia clássica que Faetonte, filho do Sol e de Clímene, ao 
ter tardiamente reconhecida a sua paternidade, pediu e obteve do pai permissão para conduzir por um dia o carro do sol. No momento em que a Aurora abria, com os seus dedos cor-de-rosa, as portas do Oriente, Faetonte subiu ao carro e com ele saiu velozmente. Por imperícia, perdeu o seu controle, e como resultado produziu-se no céu um incêndio de proporções cósmicas. Zeus, para castigá-lo, abateu-o com um raio certeiro. Já morto e em chamas, Faetonte caiu no rio Erídano - que recebe atualmente o nome de Pó. A associação feita entre os cavalos e o acidente de Faetonte introduz no poema as imagens de queda, de fim, de decadência, que contribuem muito apropriadamente para a construção progressiva das idéias de agonia e morte que se vão desenhar nas estrofes seguintes. Tais imagens colaboram, assim, para a descrição do pôr do sol.

Se na canção anterior o Sol recém-nascido era embalado em seu berço pela deusa Aurora, quem o recebe no início de sua agonia, nesta canção, são os braços cristalinos de Anfitrite, a deusa do mar. A palavra cristal e as que dela derivam exprimem, na poética barroca, as idéias de transparência e brancor: substituem uma série de palavras que expressam uma dessas condições, chegando a significar, em contextos determinados, água, tez branca, olhos. O emprego do adjetivo "cristalinos", aplicado ao substantivo "brazos", no poema em estudo, evoca a imagem do mar, em que o sol se deita. A construção que resulta da associação dessas duas palavras sugere a receptividade com que o mar recebe o sol, como num abraço.

A palavra "cristal" aparece em outras passagens da canção, e em duas delas seu uso é similar àquele verificado na construção "cristalinos brazos", significando a água do mar. É o que ocorre, na primeira estância, com a construção "cristales beben”, e também na quarta, em que aparece a imagem do "cristal salado". Outra ocorrência da palavra se dá na quarta estância, que é a que retrata a agonia do sol, ou os momentos que antecedem a sua morte. No último verso dessa estrofe, a "urna de cristal", além de ser metáfora do mar, o é também do túmulo que recebe o "cuerpo de oro" do sol.

Nessa construção progressiva da idéia de morte do dia surgem outras imagens mitológicas a ela relacionadas. Assim, é na agonia que encontramos Apolo, o condutor do carro do sol, no momento em que é sepultado na "urna de cristal", seu "túmulo mortal". Por esse motivo comparecem ao poema ainda as figuras mitológicas de Héspero e Citeréia, ambas usadas em referência a Vênus. $O$ primeiro, filho de Aurora e de Atlas, personificava o planeta Vênus, que a um só tempo corresponde à estrela da manhã e à estrela da tarde. Segundo a mitologia, Héspero foi o primeiro a escalar a montanha de Atlas para dali contemplar as estrelas. Arrebatado por uma tempestade, desapareceu, transformando-se na estrela que, a cada tarde, traz para todos o repouso da noite. Com a menção a esse mito, novamente realiza o poema a idéia de queda, de finitude. Quanto a Citeréia, também esse termo se relaciona à deusa da beleza e do amor, funcionando como um epíteto seu, uma vez que se deriva da ilha Citera, onde havia um famoso templo em honra de Vênus.

Se na primeira canção a vitalidade de todas as coisas se deve ao surgimento do sol, nesta segunda ao seu desaparecimento corresponde a idéia de luto. De igual modo, se o primeiro poema se caracteriza pelas idéias de luminosidade, calor, energia, vida, dia, o segundo poema, por oposição, se caracteriza pelas imagens de sombra, frio, cansaço, morte, noite. Se a primeira está marcada por um tom ascendente, se nela tudo se eleva, o tom da segunda é descendente, nela tudo decai. 
Tal como se verificou na canção cujo tema é a alvorada, também nesta, que tem no ocaso o seu motivo, Anarda comparece no envio. Neste último caso, porém, nenhuma recomendação é feita à canção. $\mathrm{O}$ poeta apenas lhe dirige uma melancólica constatação: a de que Anarda, seu sol, oculta-se nas trevas da angústia e do sofrimento - a ausência dela é noite para ele.

\section{A)}

\section{RESUMEN}

El presente artículo tiene como objeto el examen de dos canciones escritas en español por el poeta Manuel Botelho de Oliveira, y publicadas en la obra Música do Parnasso, de 1705. En dichas canciones, como sucede con otros poemas de Botelho de Oliveira, la mitología clásica comparece como indicio de la adhesión al código literario de su tiempo. Este esfuerzo del poeta baiano por incluirse en el canon de la poesía de la época representó importante marco para la literatura brasilera.

\section{P A L A VRAS - C LA VE}

Literatura brasilera, Barroco, Manuel Botelho de Oliveira

\section{REFERÊNCIAS}

BAEHR, Rudolf. Manual de versificación española. Madrid: Gredos, 1989.

BERTI, Luciano et al. L'Art a Firenze: I capolavori dele gallerie e musei. Firenze: Bonechi Editore, 1973.

CAMPOS, Geir. Pequeno dicionário de arte poética. Rio de Janeiro: Conquista, 1960, 220 p. HOMERO. MENDES, Manuel Odorico; BUENO, Silveira. A Odisseia. 3. ed. São Paulo: Atena, 1960. $331 \mathrm{p}$.

LESSING, G. Ephraim. Laocoonte. Madrid: Editorial Nacional, 1977. 461 p.

MARTINS, António Coimbra. Canção. In: COELHO, Jacinto do Prado (Org.). Dicionário de literatura. 3. ed. Porto: Figueirinhas, 1978. v. I. p. 140-141.

MOISÉS, Massaud. A criação literária: poesia. 3. ed. São Paulo: Cultrix, 1997.

OLIVEIRA, Manuel Botelho de; NASCENTES, Antenor. Música do Parnasso: dividida em quatro coros de rimas portuguesas, castelhanas, italianas e latinas. Rio de Janeiro: Instituto Nacional do Livro, 1953. Tomo I.

WÖFFLIN, Heinrich. Forma fechada e forma aberta. In: . Conceitos fundamentais da história da arte: o problema da evolução dos estilos na arte mais recente. 4. ed. São Paulo: Martins Fontes, 2000. p. 167-209. 